\title{
Neuroprotective Properties of Glycosaminoglycans: Potential Treatment for Neurodegenerative Disorders
}

\author{
B. Dudas ${ }^{a} \quad$ M. Rose ${ }^{b} \quad$ U. Cornellib $\quad$ A. Pavlovich ${ }^{b} \quad$ I. Hanin ${ }^{b}$

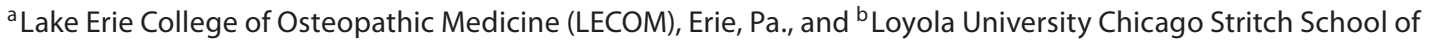 \\ Medicine, Maywood, III., USA
}

\section{Key Words}

Glycosaminoglycans, neuroprotective properties ·

Proteoglycans • Neuroparin • Alzheimer's disease • Amyloid

\begin{abstract}
Previous studies suggest that proteoglycans and glycosaminoglycans (GAGs) may play an important role in the pathogenesis and/or alleviation of neurodegenerative disorders, including Alzheimer's disease (AD). Proteoglycans increase the formation of neurofibrillary tangles, and stimulate the aggregation of $\beta$-amyloid $(A \beta)$. This effect, on the other hand, is believed to be competitively inhibited by certain GAGs. Over the past few years, we have examined the neuroprotective properties of Neuroparin (C3), a low-molecularweight GAG (approx. 2.1 kDa), in animal models of lesions characteristic of AD. Neuroparin is composed of 4-10 oligosaccharides, and it is derived from heparin involving depolymerization of heparin by gamma irradiation. In our experiments, Neuroparin protected against cholinergic lesions induced by intracerebroventricular injection of a specific cholinotoxin, AF64A, in rats. Administration of Neuroparin attenuated AF64A-stimulated, low-affinity nerve growth factor receptor-immunoreactive axonal varicosities in the rat septum, and increased arborization of hippocampal CA1 neurons. Neuroparin also reduced the septal caspase $3 \mathrm{im}$ munoreactivity induced by AF64A treatment. Moreover,
\end{abstract}

Neuroparin reduced tau 2 immunoreactivity in the rat hippocampus, stimulated by intra-amygdaloid injection of $A \beta_{25-35}$. These findings are in good agreement with our previous data indicating a neuroprotective role of GAGs. These results, plus others, all suggest that Neuroparin may possess neuroprotective properties against many of the characteristic neural lesions in AD. Since our pharmacokinetic studies revealed that Neuroparin is capable of crossing the bloodbrain barrier, Neuroparin may, conceivably, open an entirely new avenue in the treatment of neurodegenerative disorders. Phase I studies have been completed, and have proven to be extremely supportive in that regard.

Copyright $\odot 2008$ S. Karger AG, Basel

\section{Proteoglycans, Glycosaminoglycans and Alzheimer's Disease}

Previous reports suggest that proteoglycans (PGs) may play a pivotal role in the pathogenesis of Alzheimer's disease (AD). The general structure of PGs involves a protein core and glycosaminoglycan (GAG) side chains attached to the core protein (fig. 1). PGs exhibit high affinity for $\beta$-amyloid $(A \beta)$, accelerateamyloid fibril formation, and maintain fibril stability [1]. Moreover, PGs appear to protect $A \beta$ against proteolysis in vitro [2] and in tissue cultures [3]. There is a common consensus that these ef-

\section{KARGER}

(C) 2008 S. Karger AG, Basel

Fax +41613061234 E-Mail karger@karger.ch www.karger.com
Bertalan Dudas, $\mathrm{MD}, \mathrm{PhD}$

Lake Erie College of Osteopathic Medicine (LECOM)

1858 West Grandview Blvd

Erie, PA 16509 (USA)

Tel. +1 814866 8142, Fax +1 814866 8411, E-Mail bdudas@lecom.edu 


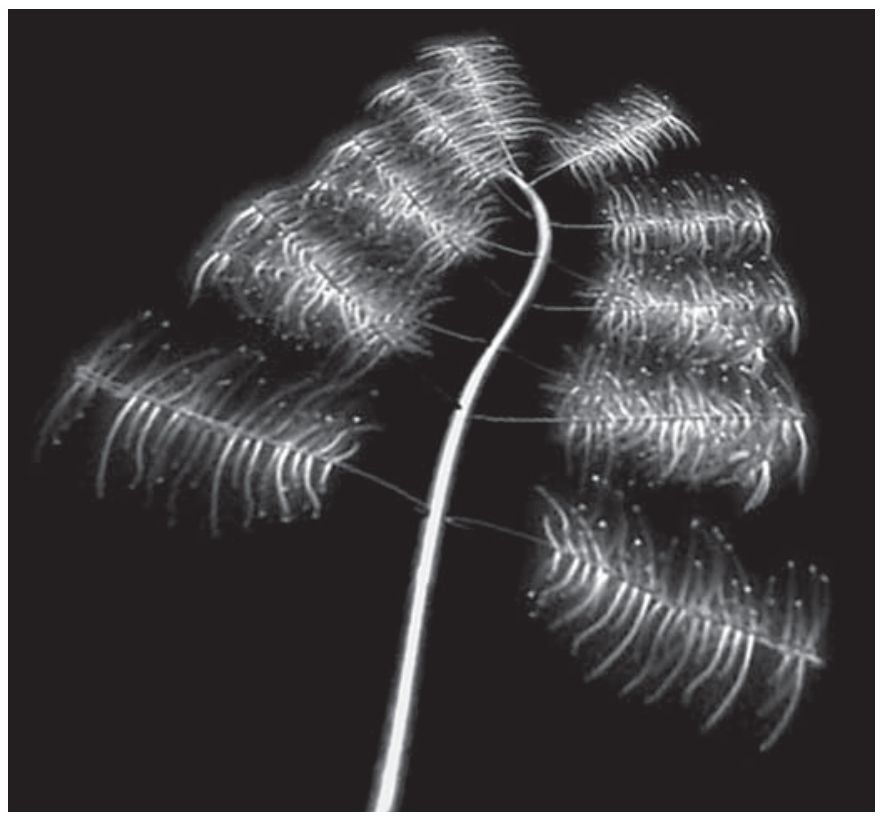

Fig. 1. General structure of PGs. PGs are typically composed of a protein core to which GAG side chains are attached. The base of the protein core is anchored to GAG hyaluronic acid.

fects of PGs facilitating the deposition of amyloid plaques are inhibited by low-molecular-weight GAGs $[2,4]$. Since GAG side chains are common constituents of PGs, the mechanism of this inhibition may involve competition of the molecules for the binding sites. In addition, GAGs inhibit the aggregation of $A \beta$ [5], the secretion of amyloid precursor protein [6], and $A \beta$ toxicity itself $[7,8]$.

\section{Chemical Characteristics of Neuroparin (C3)}

Low-molecular-weight GAGs for use in the therapy of neurodegenerative disorders are mixtures of sulfated oligosaccharide chains with different molecular weights; consequently the standardization and reproducibility of these compounds is extremely critical. In order to study the putative beneficial effects of GAGs, in our studies we used a low-molecular-weight GAG mixture, Neuroparin (also called C3). Neuroparin is prepared by a unique process involving depolymerization of heparin by gamma irradiation, followed by selective isolation of the required product. This consists of a standardized mixture of highly sulfated dextrose oligosaccharides, with hexa- and octasaccharides dominating (fig. 2), resulting in an average molecular weight of $2.1 \mathrm{kDa}$.

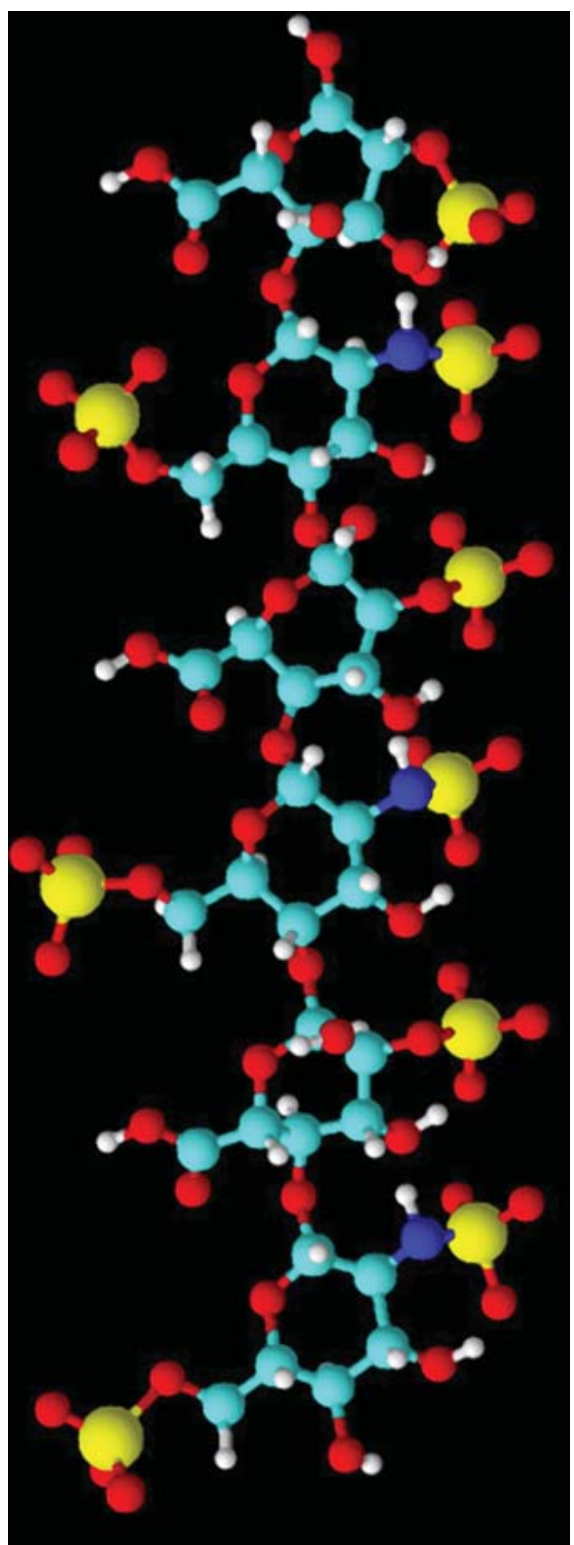

Fig. 2. Hexasaccharide component of Neuroparin (C3). The saccharide backbone is highly sulfated.

An important consideration regarding GAG administration for therapeutic purposes is the extent of bioavailability of the administered GAGs in the central nervous system, and hence their ability to penetrate the bloodbrain barrier. Our previous studies revealed that Neuroparin crosses the blood-brain barrier [9]; thus, it can be administered peripherally in order to achieve central neuroprotective effects. 


\section{Biological Effects of Neuroparin on Animal Models of Lesions Characteristic of AD}

\section{Choline-Deficient Animal Model}

One of the major characteristic features of $\mathrm{AD}$ is the lesion of cholinergic neurons in the central nervous system. This cholinergic deficit can be simulated in an animal model originally described by Mantione et al. [10], which employs intraventricular administration of a specific cholinotoxin, AF64A. Since AF64A does not cross the blood-brain barrier, we administered it stereotaxically into the lateral ventricles, at the doses that are selective for cholinotoxicity ( $2 \mathrm{nmol} / \mathrm{side}$ ). Immunohistochemical detection of the cholinergic elements revealed that administration of AF64A induced cholinergic damage in the rat septum and cingulum bundle. This lesion was characterized by the appearance of abnormally enlarged cholinergic axon varicosities, and by a reduction of the number of cholinergic perikarya in the rat brain.

In our studies, we used this choline-deficient animal model, in order to test the putative neuroprotective attributes of low-molecular-weight GAGs [11, 12]. Administration of Neuroparin 7 days before and 7 days after AF64A administration significantly reduced the abnormal cholinergic axon varicosities and blocked the AF64Ainduced cholinergic neuronal loss in the rat septum. Since Neuroparin administration only before or only after the surgery did not significantly alter the AF64A-induced cholinergic damage, it is conceivable that Neuroparin possesses both neuroprotective and neuroreparative properties.

\section{Tau 2 Animal Model}

Flame-shaped tangle deposition in cortical neurons is one of the major hallmarks of AD. These tangles are composed of the hyperphosphorylated form of the tau protein, a peptide that is normally present in the brain. There is evidence that tau protein deposition is induced by abnormally cleaved amyloid fragments that can be commonly detected in the brain of $\mathrm{AD}$ patients as amyloid plaques. Indeed, in the animal model of tau protein deposition, described by Sigurdsson et al. [13], unilateral injection of $A \beta_{25-35}$ into the amygdala induced the appearance of tau-2-immunoreactive cells in the ipsilateral rat hippocampus. Oral administration of Neuroparin (25 $\mathrm{mg} / \mathrm{kg}$, twice daily), starting 3 days before the amyloid injection and continuing for 14 days after the surgery, significantly reduced the abnormal tau 2 immunoreactivity in the rat hippocampus [14]. The effectiveness of the oral dose further emphasizes the ability of Neuroparin to cross the blood-brain barrier.

\section{Reactive Astrocytosis}

In addition to the tau 2 immunoreactivity, intra-amygdaloid administration of $A \beta_{25-35}$ also induced reactive astrocytosis around the injected deposit. Although the morphology of the deposit in the amygdala did not noticeably change in the first 4 weeks of the experiment, the number of glial fibrillary acidic protein-immunoreactive astrocytes in the close vicinity of the amyloid deposit was considerably increased. Administration of Neuroparin during a 32-day period after the amyloid injection significantly reduced this intra-amygdaloid glial fibrillary acidic protein immunoreactivity.

\section{Effect of GAGs on Apoptosis}

\section{Apoptosis and $A D$}

Apoptosis (programmed cell death) is a process that is initiated in order to avert inflammation associated with necrotic processes by safely removing damaged cells from injury sites. The initiation of apoptotic processes can occur via intrinsic or extrinsic pathways, involving internal or external stimuli. Intrinsic pathways typically involve mitochondrial damage, when mitochondrial cytochrome $\mathrm{C}$ activates cytoplasmic initiator caspases. The extrinsic pathway is triggered by specific ligands ('death ligand') binding to 'death receptors' on the cell surface, and this event activates the initiator caspases in the cytoplasm. Both the internal and external pathways eventually activate caspase 3 that eventually leads to degradation of DNA in the nucleus, reducing the cell into compact units that can be easily removed from the tissue.

Extensive research indicates that apoptotic processes play a pivotal role in the pathogenesis of neurodegenerative disorders including AD. Apoptosis-related proteins are expressed and altered in brains of patients with $\mathrm{AD}$ $[15,16]$. Moreover, neuronal caspase 3 is activated in $\mathrm{AD}$ [17], suggesting that caspase inhibition may be used to improve the cognitive functions of $\mathrm{AD}$ patients and slow down the progression of the disease. Since the cytochrome $C$ levels are unaffected in the frontal cortex of $A D$ patients [16], there is a general consensus that the majority of the cell loss associated with $\mathrm{AD}$ is triggered by 'death ligand'-'death receptor' interaction, involving multiple processes with or without caspase 3 activation, which eventually leads to cell death and removal. 
GAGs and Apoptosis

Previous studies indicate that GAGs may play a modulatory role in the apoptotic processes. Heparin inhibits glomerular cell apoptosis in cell culture [18] and attenuates trophoblast apoptosis [19]. The GAG hyaluronan attenuates apoptosis induced by dexamethasone in malignant multiple myeloma cells [20]. Moreover, chondroitin sulfate and heparan sulfate attenuate apoptosis in fetal lung fibroblasts [21]. In contrast, numerous data indicate that certain GAGs may induce apoptosis. Thus, they may contribute to the natural processes of the body for the elimination of tumor cells. Heparin has an apoptotic effect on human hepatoma cells [22], human nasopharyngeal carcinoma cells [23] and peripheral blood neutrophils [24], possibly by interfering with transcription factor function [25]. Derivatives of heparin and chondroitin sulfate induce apoptosis of myeloma and breast cancer cells in vitro [26]. Chondroitin sulfate also induces apoptosis of chondrocytes [27].

\section{Effect of Neuroparin on AF64A-Induced Caspase 3 Activity}

Our previous studies revealed that AF64A administration induces caspase 3 activity in the septal area of the rat brain [28]. The location and morphology of the caspase-3-immunoreactive structures correspond to those of the damaged cholinergic elements after AF64A administration, indicating that apoptotic processes may play a pivotal role in the AF64A-induced cholinergic lesion. Neuroparin administration significantly reduced AF64A-induced caspase 3 activity, suggesting that the cholinoprotective properties of Neuroparin may be based on the inhibition of apoptotic processes.

\section{Effect of Neuroparin on Dendritic Branching}

It has previously been described that intra-amygdaloid injection of $A \beta_{25-35}$ significantly reduced dendritic spine density of CA1 pyramidal cells in the rat hippocampus, visualized with Golgi silver impregnation [29]. Interestingly, Neuroparin treatment following $A \beta_{25-35}$ administration had a minor effect on the spine density of the cells; however, administration of Neuroparin alone increased dendritic branching of the hippocampal pyramidal cells [29]. These results indicate that Neuroparin appears to possess a significant neurotrophic effect on hippocampal neurons.

Neuroprotective Properties of

Glycosaminoglycans

\section{Effect of Neuroparin on Septal p75 Expression Induced by AF64A}

The remarkable impact of Neuroparin on dendritic density raises the possibility that Neuroparin, and possibly other low-molecular-weight GAGs, induce dendritic branching via neurotrophic factors or the receptors of these factors. In our previous studies, we examined the effect of Neuroparin on nerve growth factor receptor p75 expression [30]. AF64A administration induced p75 expression in the rat septum; the morphology and the pattern of the p75-immunoreactive structures exerted a remarkable similarity to those of the cholinergic structures damaged by AF64A. These data indicate a possible compensatory mechanism of lesioned neurons directed towards neurorepair, via p75 receptor upregulation.

Administration of Neuroparin 7 days before and 7 days after AF64A injection significantly reduced p75 expression in the rat septum. These findings suggest that: (a) Neuroparin reduces p75 expression via attenuating the lesion induced by AF64A, or (b) Neuroparin may have a direct effect on neurotrophic factor metabolism. These findings may explain the significant neurotrophic properties of Neuroparin, previously described in our studies.

\section{Biological Effect of Alternative GAGs: K3, D3, H3}

Early studies in human subjects revealed that administration of a mixture of low-molecular-weight GAGs, Ateroid ${ }^{\circledR}$, improved the cognitive functions of elderly patients [31, 32]. However, since Ateroid is a mixture, it is uncertain which component is responsible for the cognitive improvements. We have previously described the remarkable neuroprotective, neuroreparative and neurotrophic effects of a component of Ateroid, Neuroparin. Since Ateroid is a mixture of heparin, heparan, dermatan, and chondroitin sulfates, we reasoned that gamma irradiation of these components of Ateroid may also be of potential therapeutic benefit in $\mathrm{AD}$, when produced using the same method as that for generating C3. Consequently, components $\mathrm{H} 3, \mathrm{D} 3$, and $\mathrm{K} 3$ were produced from heparan sulfate, dermatan sulfate and chondroitin sulfate, respectively, by gamma irradiation. Although these components exerted some neuroprotective/neuroreparative properties on the AF64A-induced cholinergic lesion, their effect was significantly less than that of Neuroparin [33].

Neurodegenerative Dis 2008;5:200-205 


\section{Discussion and Summary}

Neuroparin appears to exert definite neuroprotective/ neuroreparative properties in several animal models that have been developed in order to simulate the major histological hallmarks of AD. Neuroparin attenuated AF64A-induced cholinergic deficit, nerve growth factor receptor p75 expression, and caspase 3 immunoreactivity in the rat septum. Neuroparin also protected against $A \beta_{25-35}$-induced tau 2 immunoreactivity in the rat hippocampus, and reduced the astrocytosis induced by $A \beta$ injection. Moreover, Neuroparin exerted neurotrophic activity in the rat by increasing arborization and spinal density of hippocampal pyramidal cells.

There is a general consensus that GAGs exert their crucial effects for neuronal survival via competitively attenuating the effects of PGs. However, numerous other factors may play an important role in the neuroprotec- tive/neuroreparative properties of Neuroparin. GAGs are the major constituents of the glycocalyx, thus, it is plausible that Neuroparin may increase/restore the glycocalyx layer of the cell, making the cells less sensitive to various lesions. Neuroparin may also influence nerve growth factor release and nerve growth factor receptor expression, increasing dendritic arborization and facilitating neuroregeneration. Although these possible mechanisms require further studies, the neuroprotective properties of Neuroparin appear to be well established, thus making it a promising prospect for the treatment of $\mathrm{AD}$.

\section{Acknowledgement}

The present study has been supported by NIA/STTR grant 1R41-AG15740-02.

\section{References}

1 Castillo GM, Ngo C, Cummings J, Wight TN, Snow AD: Perlecan binds to the betaamyloid proteins (A beta) of Alzheimer's disease, accelerates A beta fibril formation, and maintains A beta fibril stability. J Neurochem 1997;69:2452-2465.

-2 Gupta-Bansal R, Frederickson RC, Brunden KR: Proteoglycan-mediated inhibition of A beta proteolysis. A potential cause of senile plaque accumulation. J Biol Chem 1995;270: 18666-18671.

- 3 Shaffer LM, Dority MD, Gupta-Bansal R, Frederickson RC, Younkin SG, Brunden KR: Amyloid beta protein (A beta) removal by neuroglial cells in culture. Neurobiol Aging 1995; 16:737-745.

-4 Leveugle B, Scanameo A, Ding W, Fillit H: Binding of heparan sulfate glycosaminoglycan to beta-amyloid peptide: inhibition by potentially therapeutic polysulfated compounds. Neuroreport 1994;5:1389-1392.

5 Kisilevsky R, Lemieux LJ, Fraser PE, Kong X, Hultin PG, Szarek WA: Arresting amyloidosis in vivo using small-molecule anionic sulphonates or sulphates: implications for Alzheimer's disease. Nat Med 1995;1:143-148.

6 Leveugle B, Ding W, Laurence F, Dehouck MP, Scanameo A, Cecchelli R, et al: Heparin oligosaccharides that pass the blood-brain barrier inhibit beta-amyloid precursor protein secretion and heparin binding to betaamyloid peptide. J Neurochem 1998;70:736744 .
7 Pollack SJ, Sadler II, Hawtin SR, Tailor VJ, Shearman MS: Sulfonated dyes attenuate the toxic effects of beta-amyloid in a structurespecific fashion. Neurosci Lett 1995;197: 211-214.

8 Pollack SJ, Sadler II, Hawtin SR, Tailor VJ, Shearman MS: Sulfated glycosaminoglycans and dyes attenuate the neurotoxic effects of beta-amyloid in rat PC12 cells. Neurosci Lett 1995;184:113-116.

\$ Ma Q, Dudas B, Hejna M, Cornelli U, Lee JM, Lorens S, et al: The blood-brain barrier accessibility of a heparin-derived oligosaccharide C3. Thromb Res 2002;105:447-453.

10 Mantione CR, Fisher A, Hanin I: The AF64atreated mouse: possible model for central cholinergic hypofunction. Science 1981;213: 579-580.

11 Rose M, Dudas B, Cornelli U, Hanin I: Protective effect of the heparin-derived oligosaccharide C3, on AF64A-induced cholinergic lesion in rats. Neurobiol Aging 2003;24: 481-490.

12 Rose M, Dudas B, Cornelli U, Hanin I: Glycosaminoglycan $\mathrm{C} 3$ protects against AF64Ainduced cholinotoxicity in a dose-dependent and time-dependent manner. Brain Res 2004;1015:96-102.

$\longrightarrow 13$ Sigurdsson EM, Lorens SA, Hejna MJ, Dong XW, Lee JM: Local and distant histopathological effects of unilateral amyloid-beta 25 35 injections into the amygdala of young F344 rats. Neurobiol Aging 1996;17:893901.
14 Dudas B, Cornelli U, Lee JM, Hejna MJ, Walzer M, Lorens SA, et al: Oral and subcutaneous administration of the glycosaminoglycan C3 attenuates Abeta(25-35)-induced abnormal tau protein immunoreactivity in rat brain. Neurobiol Aging 2002;23:97-104.

15 Engidawork E, Gulesserian T, Seidl R, Cairns N, Lubec G: Expression of apoptosis related proteins in brains of patients with Alzheimer's disease. Neurosci Lett 2001;303:7982.

16 Engidawork E, Gulesserian T, Yoo BC, Cairns N, Lubec G: Alteration of caspases and apoptosis-related proteins in brains of patients with Alzheimer's disease. Biochem Biophys Res Commun 2001;281:84-93.

17 Selznick LA, Holtzman DM, Han BH, Gokden M, Srinivasan AN, Johnson EM, et al: In situ immunodetection of neuronal caspase-3 activation in Alzheimer disease. J Neuropathol Exp Neurol 1999;58:1020-1026.

18 Ishikawa Y, Kitamura M: Inhibition of glomerular cell apoptosis by heparin. Kidney Int 1999;56:954-963.

19 Bose P, Black S, Kadyrov M, Weissenborn U, Neulen J, Regan L, et al: Heparin and aspirin attenuate placental apoptosis in vitro: implications for early pregnancy failure. Am J Obstet Gynecol 2005;192:23-30.

20 Vincent T, Molina L, Espert L, Mechti N: Hyaluronan, a major non-protein glycosaminoglycan component of the extracellular matrix in human bone marrow, mediates dexamethasone resistance in multiple myeloma. Br J Haematol 2003;121:259-269. 
-21 Cartel NJ, Post M: Abrogation of apoptosis through PDGF-BB-induced sulfated glycosaminoglycan synthesis and secretion. Am J Physiol Lung Cell Mol Physiol 2005;288: L285-L293.

-22 Karti SS, Ovali E, Ozgur O, Yilmaz M, Sonmez M, Ratip S, et al: Induction of apoptosis and inhibition of growth of human hepatoma HepG2 cells by heparin. Hepatogastroenterology 2003;50:1864-1866.

-23 Li HL, Ye KH, Zhang HW, Luo YR, Ren XD, Xiong AH, et al: Effect of heparin on apoptosis in human nasopharyngeal carcinoma CNE2 cells. Cell Res 2001;11:311-315.

-24 Manaster J, Chezar J, Shurtz-Swirski R, Shapiro G, Tendler Y, Kristal B, et al: Heparin induces apoptosis in human peripheral blood neutrophils. Br J Haematol 1996;94: 48-52.

-25 Berry D, Lynn DM, Sasisekharan R, Langer R: Poly(beta-amino)esters promote cellular uptake of heparin and cancer cell death. Chem Biol 2004;11:487-498.
26 Pumphrey CY, Theus AM, Li S, Parrish RS, Sanderson RD: Neoglycans, carbodiimidemodified glycosaminoglycans: a new class of anticancer agents that inhibit cancer cell proliferation and induce apoptosis. Cancer Res 2002;62:3722-3728.

27 Bali JP, Cousse H, Neuzil E: Biochemical basis of the pharmacologic action of chondroitin sulfates on the osteoarticular system. Semin Arthritis Rheum 2001;31:58-68.

28 Dudas B, Lemes A, Cornelli U, Hanin I: Prospective role of glycosaminoglycans in apoptosis associated with neurodegenerative disorders; in Fisher A, Hanin I, Stocchi F, Memo M (eds): Advances in Alzheimer's and Parkinson's Disease: Advances, Progress, and Perspectives. New York, Springer, 2007.

29 Mervis RF, McKean J, Zats S, Gum A, Reinhard R, Dudas B, et al: Neurotrophic effects of the glycosaminoglycan C3 on dendritic arborization and spines in the adult rat hippocampus: a quantitative Golgi study. CNS Drug Rev 2000;6:44-46.
30 Dudas B, Rose M, Cornelli U, Hanin I: Low molecular weight glycosaminoglycan C3 attenuates AF64A-stimulated, low-affinity nerve growth factor receptor-immunoreactive axonal varicosities in the rat septum. Brain Res 2005;1033:34-40.

31 Conti L, Re F, Lazzerini F, Morey LC, Ban TA, Santini V, et al: Glycosaminoglycan polysulfate (Ateroid) in old-age dementias: effects upon depressive symptomatology in geriatric patients. Prog Neuropsychopharmacol Biol Psychiatry 1989;13:977-981.

32 Conti L, Placidi GF, Cassano GB: Ateroid in the treatment of dementia: results of a clinical trial. Mod Probl Pharmacopsychiatry 1989;23:76-84.

33 Dudas B, Rose M, Cornelli U, Ambrosi LD, Cornelli M, Hanin I: Glycosaminoglycans and neuroprotection: effect on cholinergic neurodegeneration; in Hanin I, Fisher A, Cacabelos R (eds): Alzheimer's and Parkinson's Diseases: New Prospectives. London, Dunitz, 2004, pp 227-234. 